10 years ESJ

Special edition

\title{
Efectos de la Pandemia del COVID-19 en el Comportamiento del Consumidor Mexicano: Hábitos de Compra de la Canasta Básica
}

\author{
Ruth Josefina Alcántara Hernández \\ Arlen Cerón Islas \\ Juan Gabriel Figueroa Velázquez \\ Universidad Autónoma del Estado de Hidalgo, Mexico
}

Doi: $10.19044 /$ esj.2021.v17n4p165

Submitted: 28 October 2020

Accepted: 23 December 2020

Published: 07 February 2021
Copyright 2021 Author(s)

Under Creative Commons BY-NC-ND

4.0 OPEN ACCESS

Cite As:

Alcántara Hernández J.R., Islas C.A. \& Figueroa Velázquez G.J. (2021). Efectos de la Pandemia del COVID-19 en el Comportamiento del Consumidor Mexicano: Hábitos de Compra de la Canasta Básica. European Scientific Journal, ESJ, 17(4), 165.

https://doi.org/10.19044/esj.2021.v17n4p165

\section{Resumen}

El presente artículo tiene como objetivo realizar un análisis sobre el cambio de hábitos del consumidor en tiempos de pandemia de la $\mathrm{Cd}$. de Pachuca, Hidalgo, y su zona metropolitana, principalmente relacionado con las elecciones de compra que realizan sobre los productos de la canasta básica, basándose en frecuencia y lugar. Para lograrlo se tomó como base la teoría de la motivación humana de Maslow, y posteriormente se realizó una encuesta aleatoria a los consumidores que tienen poder de compra en sus familias, alcanzando un total de 345 personas encuestadas. En este estudio se pudo encontrar que los hábitos de compra han tenido poca variación en cuanto al lugar de compra, incrementándose el consumo en tiendas de abarrotes y de conveniencia; la frecuencia de compra ha disminuido, así como el presupuesto asignado ha tenido variaciones; en las revisiones realizadas se pudo observar que los pagos electrónicos han sufrido un incremento. Los resultados obtenidos y las conclusiones a las que se llegan permiten visualizar la importancia que tiene para las empresas de cualquier tamaño el desarrollo de estrategias que permitan reinventarse y acceder a los mercados de manera exitosa, adaptándose a la "nueva normalidad" de los consumidores. 
Palabras clave: Consumidor, hábitos, confinamiento

\title{
Effects of the COVID-19 Pandemic on the Behavior of the Mexican Consumer: Buying Habits of the Basic Basket
}

\author{
Ruth Josefina Alcántara Hernández \\ Arlen Cerón Islas \\ Juan Gabriel Figueroa Velázquez \\ Universidad Autónoma del Estado de Hidalgo, Mexico
}

\begin{abstract}
This paper focuses on carrying out an analysis on the change in consumer habits during the pandemic period in the City of Pachuca, Hidalgo, and its metropolitan area. This is mainly related to the choices they make about the products of the basic basket, based on frequency and location. To achieve this, Maslow's theory of human motivation was taken as a basis. A random survey was also conducted among consumers who have purchasing power in their families, thus a total of 345 people were surveyed. In this study, it was found that shopping habits have had little variation in the aspect of the place of purchase. This has led to increase in grocery and convenience stores, the frequency of purchase has decreased, and the assigned budget has had variations. In the reviews carried out, it was observed that electronic payments have also suffered an increase. The results obtained and the conclusions reached made it possible to visualize the importance for companies of any size to develop strategies that allow them to reinvent themselves and successfully access markets, in order to adapt to the "new normal" of consumers.
\end{abstract}

Keywords: Consumer, habits, confinement

\section{Introduction}

De acuerdo con la con las proyecciones de la Comisión Económica Para América Latina y el Caribe (CEPAL) y la Organización Panamericana de la Salud (OPS), a consecuencia de los estragos generados por el virus denominado COVID-19, la región en mención experimentará una disminución del $9.1 \%$ del producto interno bruto (PIB). Las medidas de distanciamiento social que se han implementado en los diversos países, tienen un impacto negativo en términos de empleo y con ello de ingresos en las familias, de tal manera que este retroceso del PIB, motivará a un aumento del número de desempleados para alcanzar más de 44 millones de personas (CEPAL-OPS, 2020). 
Si bien es cierto que el impacto de la crisis, generada por la pandemia del COVID-19, afecta a toda la economía en su conjunto, se espera un mayor impacto en las micro, pequeñas y medianas empresas, lo cual adquiere mayor relevancia si consideramos que estas representan el $99.5 \%$ de las empresas de América Latina, al tiempo que generan el $61 \%$ del empleo de la región (CEPAL, 2020). Esta misma organización, ha observado que la crisis ha motivado una reducción del ingreso de los consumidores y a modificaciones en sus patrones de consumo, impactando negativamente en el mercado de automóviles, electrodomésticos, vivienda y muebles; mientras que los segmentos de productos de limpieza, alimentos duraderos, televisión vía internet y telecomunicaciones han experimentado un impacto positivo.

En el mismo sentido, Sheth (2020) expresa que los hábitos de consumo pueden modificarse de acuerdo a las circunstancias: en algunos casos pueden deberse a las condiciones familiares o sociales (casarse, tener hijos, cambiar el lugar de residencia), al avance tecnológico y de las telecomunicaciones en particular, y finalmente debido a eventos menos predecibles como es el caso de la pandemia generada por el COVID-19.

En México se declara la contingencia de confinamiento a causa de la pandemia mundial por COVID-19 en marzo del 2020; lo cual obliga a la población a guardar la cuarentena en casa, evitando salir a actividades no esenciales y por tanto cambiar sus hábitos y estilo de vida. Esta situación que se ha alargado por meses, conlleva un cambio en los hábitos de compra de los consumidores, quienes estaban acostumbrados a comprar en puntos de venta tales como supermercados, mercados tradicionales, central de abastos y tianguis informales principalmente de los productos contenidos en la "canasta básica"; ahora estos representan un sitio peligroso ante la gravedad del virus. Por lo cual, las empresas empiezan a ofrecer distintas modalidades de compra y los consumidores a variar en su preferencia, frecuencia de compra, forma de pago y presupuesto asignado.

En tal sentido es pertinente plantear la siguiente pregunta de investigación ¿Han cambiado los hábitos de compra de los productos de la canasta básica del consumidor de la Cd. de Pachuca, Hidalgo México, en términos de lugar y frecuencia como consecuencia del confinamiento de la pandemia por COVID-19?

Un concepto esencial que se establece es el de "Canasta Básica" que se define como el conjunto de alimentos suficientes para satisfacer las necesidades de un hogar promedio, que en México es de 3.7 integrantes, según datos del Instituto Nacional de Estadística, Geografía e Informática - INEGI (2015). Para efectos de esta investigación, los productos de la canasta básica mexicana dada por el Consejo Nacional de Evaluación de la Política de Desarrollo Social CONEVAL (Consejo Nacional de Evaluación de la Política 
de Desarrollo Social, 2012) y que siguen siendo las utilizadas para estudios de este tipo son los siguientes:

1) Cereales, semillas y leguminosas: tortillas, masa de maíz, harina de trigo, pan dulce, pan blanco, garbanzos, soya, arroz, galletas, cereales en la caja, frijol, avena, lentejas, tostadas, golosinas de cereal y semillas.

2) Enlatados y despensa en general: agua purificada, azúcar, aceite de cocina, atún, sardina, chiles en lata, café en grano, café soluble, sopa de pasta, chocolate, sal de mesa, puré de tomate, concentrado para agua, gelatina, refrescos.

3) Lácteos y carne: leche en caja, leche en polvo, pescado, mariscos, huevo, queso, pollo, carne de res, carne de cerdo, carne de cordero, manteca de puerco.

4) Frutas y verduras: fruta variada y de temporada, verdura variada y de temporada, jamaica y tamarindo natural, frutas deshidratada.

5) Productos de limpieza del hogar: papel higiénico, detergente de lavandería, pilas, esponjas y cepillos para tallar, cloro, vinagre, desinfectante, otros.

6) Productos de limpieza personal: jabón de tocador, pasta de dientes, desodorantes, shampoo, crema corporal, toallas sanitarias, otros.

\section{Necesidades y el Comportamiento del Consumidor}

La Teoría de la Motivación Humana, (Maslow, 1943; citado en Quintero, s/d) propone una jerarquía de necesidades y factores que motivan a las personas; lo cual modela cinco categorías de necesidades y se construye con un orden jerárquico ascendente de acuerdo a su importancia para la supervivencia y la capacidad de motivación. De igual forma establece que conforme el hombre satisface sus necesidades florecen otras que provocan un cambio o modificación del comportamiento del consumidor; considerando que solo cuando una necesidad está moderadamente satisfecha, se disparará una nueva necesidad influenciada por el entorno situacional (Colvin \& Rutland, 2008).

Camacho (2016) establece que en el aspecto de las necesidades se hace especial énfasis dentro del término "mercadeo" debido a que su función, desde el fundamento conceptual, es la satisfacción de las mismas con un producto y/o servicio idóneo para tal fin; a partir de esta premisa es necesario abordar la jerarquía de las necesidades donde Maslow estableció que existen una serie de carencias que el ser humano satisface de manera progresiva, es decir, una vez satisfecha un nivel de necesidad de inmediato surgen otras áreas que demandan ser cubiertas.

Las dos primeras jerarquías que se abordan son: fisiológicas - la subsistencia del ser humano y la satisfacción de los instintos requeridos para 
la procreación- y de seguridad - protección del individuo según su entorno-; y estos estadios determinan el comportamiento del consumidor base; el comportamiento hace referencia a la dinámica interna y externa del individuo, que tiene lugar cuando busca satisfacer sus necesidades con bienes y servicios. Aplicado al marketing, se entiende que es el proceso de decisión y la actividad física para buscar, evaluar y adquirir bienes y servicios para satisfacer las necesidades (Wilkie, 1994).

Los consumidores pueden basar sus decisiones en un proceso cognoscitivo de búsqueda y evaluación de información del producto y las distintas opciones. Según Assael (1999) en esta decisión influyen el involucramiento y la relación de dos conceptos: toma de decisiones y hábito; lo que se considera el despertar de la necesidad la cual está influenciada por cinco variables - experiencias pasadas, características del consumidor, motivos del consumidor, influencias ambientales y estímulos de mercadotecnia.

\section{Hábitos del Consumidor Mexicano}

Marina (2012) define al hábito como esquemas mentales estables, aprendidos por repetición de actos, que facilitan y automatizan las operaciones mentales cognitivas, afectivas, ejecutivas o motoras. García (2015) hace referencia a la teoría keynesiana del consumo en donde afirma que el consumo tendría una parte que depende de la renta disponible del período y otra parte autónoma; establece que el consumo autónomo manifestaría el mínimo consumo indispensable para la supervivencia y el consumo autónomo que obedece a otras fuentes distintas a la renta disponible del período como, por ejemplo, los ahorros acumulados.

Se entiende por hábitos de consumo a los comportamientos del comprador dependiendo de los lugares donde va a realizar la compra, la frecuencia de la compra, las clases de producto que adquiere y los momentos de la compra entre muchos otros factores que influyen en la compra (Centro de investigación de mercados, 2020).

Es por ello que se plantea que hoy día los compradores son mucho más impulsivos, ya que ahora toman en cuenta la relación costo / beneficio, lo que implica que la mayoría de los consumidores buscan marcas más baratas, pero sin dejar de buscar calidad; aunado a que las personas están atentas a las promociones que ofrecen los lugares generando con esto un hábito de compra, es decir, el consumo de los productos es mayor y esto genera una mayor frecuencia de visita en el lugar (Centro de investigación de mercados, 2020).

Analítica de Retail (2018) define a los hábitos de consumo como aquellas tendencias que siguen los clientes al comprar productos y servicios. Estas tendencias provienen de una variedad de factores diferentes tanto físicos como mentales, y es menester de las organizaciones examinar los hábitos de 
los clientes, ya que son la base para construir un plan de marketing que aproveche los hábitos de compra del cliente objetivo y genere más ventas.

Esta misma organización menciona que el comercio minorista se ha convertido en una reacción en cadena continua de movimientos, eventos, experiencias y motivos. Las compras se han vuelto afines al contexto, la persona y el lugar y se han visto influenciadas por el espacio y tiempo; para el consumidor ir de compras se trata de cómo y cuándo.

En esa misma directriz Martínez (2019) menciona que el hábito de compra es el comportamiento del comprador respecto a los lugares de compra, desplazamientos, tipos de lugares visitados, frecuencia de compra, momento de la compra, clases de productos adquiridos, razones de elección, actitudes y opiniones que suele tener los establecimientos comerciales. Por lo que se establece que existen consumidores racionales que buscan en sus compras la satisfacción de una necesidad básica y por otro lado existen consumidores compulsivos que son aquellos que compran sin pensar satisfaciendo su deseo al instante;

En particular, IZA BC Staff (2018) establece que el perfil cultural del mexicano cuenta con seis características de hábitos de compra, así como diversos factores circunstanciales que modifican el perfil del consumidor como economía, política, sociedad y tecnología, estas características son:

- Diferencias socioeconómicas muy marcadas.

- El papel de la familia.

- Target infantil, el más importante.

- El crédito como instrumento de compra.

- Características de las compras en línea.

- Relación costo beneficio.

\section{El Comportamiento del Consumidor en Medio de la Pandemia por COVID-19}

Según Innovación Económica (2020), el consultor de la Dirección de Competitividad e Innovación Antonio Torres identifica los cinco principales sectores que sufrirán cambios tras la pandemia:

1) Educación: surge la necesidad de generar nuevas herramientas para mejorar la comunicación entre los actores, encontrar el modelo educativo tecnológico que se adapte a las necesidades institucionales y de los integrantes.

2) Servicios profesionales tradicionales: este sector necesitará replantear la forman en que ofertan sus servicios, con tendencias digitales, especialmente se hace referencia a contadores, abogados, psicólogos, doctores y nutriólogos. 
3) Industria wellness: la contingencia puso frente a situaciones poco gratas y un tanto negativas a algunas personas, ya que sufrieron depresión, ansiedad o comenzaron a comer de forma compulsiva, es por esta razón que en el mundo post-pandemia la industria del bienestar tendrá un gran repunte; en este caso se reinventaran los modelos de negocio cómo los servicios de meditación, yoga o cuidado personal debido al incremento de su demanda y consumo.

4) Protección de la información: la revolución en este sector es indispensable debido a que muchas empresas se vieron en la necesidad de desplazarse a la zona digital, lo que provoca que surja la necesidad de resguardar la información.

5) Proyectos sustentables: toma auge esta industria debido a que cobra importancia la perspectiva ecológica, debido a que muchas personas han realizado reflexiones de como las acciones que se realizan impactan a terceros y al entorno, se revoluciona la responsabilidad social.

El estudio de Butu et al. (2020), realizado en ciudades rurales de Rumania reporta la manera en que los consumidores en una zona semiurbana, modificaron el lugar y canales de compra de productos agrícolas, con el propósito de mantener menos acercamiento físico con personas extrañas y minimizar así las posibilidades de contagio del virus.

En este mismo contexto la agencia The Nielsen Company - Nielsen(2020), ha realizado un análisis de los cambios de consumo a nivel mundial con la finalidad de ayudar a que las empresas entiendan al consumidor en tiempos de pandemia. Ha identificado seis etapas del comportamiento del consumidor relacionadas directamente a las preocupaciones que tienen las personas con respecto al brote de COVID-19.

A continuación, se presentan las seis etapas en las que Nielsen (2020) ha clasificado los comportamientos de consumo a nivel mundial:

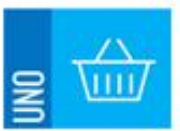

Compras Proactivas
Para la salud

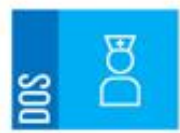

Gestión reactiva de

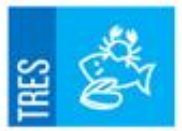

Preparación de la
despensa

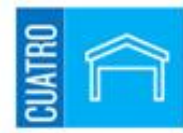

Preparación para la vida en cuarentena
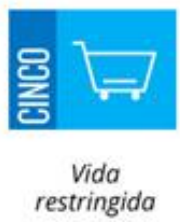

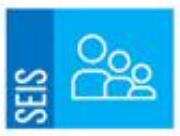

Vivir una nueva
normalidad

Figura 1. Etapas del comportamiento del consumidor Fuente: Nielsen (2020)

Por otro lado, la investigación realizada por García (2020) identifica que el $30 \%$ de la población mexicana no adopta las medidas de la cuarentena, como el uso del cubre bocas, gel antibacterial, desinfectante y la sana 
distancia, entre otros. Además, más de la mitad de la población se encuentra preocupada porque considera que la situación económica se verá muy afectada. Así mismo reporta que los habitantes de la provincia en Barcelona experimentaron una disminución en la frecuencia de compra, aumentando el porcentaje de la población que pasa a realizar solo dos visitas al lugar de compra en el periodo de un mes, o incluso solo llegan a hacer una sola compra en ese periodo de tiempo.

En el mismo sentido reportan sus resultados Butu et al.(2020), cuando señalan que, durante este periodo de contingencia, la preferencia de las compras semanales disminuyó, mientras que la preferencia por las adquisiciones cada dos semanas ha experimentado un aumento entre los consumidores rumanos estudiados.

Menciona también que esta contingencia ha tenido un gran impacto emocional en las personas, lo que ha causado un sentimiento de miedo e incertidumbre, lo que provoca un cambio significativo en las vidas. Adicionalmente el estudio reporta que un poco menos de la mitad se siente triste, pues extraña salir, tener contacto con sus amigos y/o familiares; una cuarta parte menciona que se siente enojada o frustrada, debido a las restricciones y modificaciones que han tenido que realizar en sus vidas. Muy pocos mexicanos entrevistados en el estudio sienten afecto y solidaridad por los que tienen que por obligación salir de sus casas y sólo el $2 \%$ de la muestra siente cierto entusiasmo de aprender cosas diferentes (García, 2020).

De acuerdo con Escamilla (2020) el 86.2\% de la población casada tiene como actividad de ocio ver videos en plataformas de streaming -debido al tiempo libre-; un gran porcentaje prioriza alimentos enlatados, agua embotellada y medicamentos básicos. Los mexicanos solteros priorizan en un menor porcentaje los alimentos enlatados, medicamentos básicos, agua embotellada y se puede observar un porcentaje relativamente mayor con el consumo de material de curación, agua potable, productos para la higiene del cuerpo y medicinas.

En cuanto a la frecuencia de compra se identifica que predominan las compras semanales y una décima parte de la población soltera realiza compras diarias (Escamilla, 2020); un 19.4\% de las personas ha incrementado el uso de aplicaciones de entrega a domicilio, esto para mantener la "sana distancia". Particularmente las personas solteras han cambiado sus hábitos hacia las cosas que puede hacer en casa destacándose el ver contenido, escuchar música en cualquier servicio streaming; y ver televisión de paga.

Chávez (2020) menciona que al entrar el país oficialmente en la Fase 2 de la epidemia, significa que habría una nueva evolución en los hábitos de consumo de los consumidores nacionales, ya que las compras fueron distintas entre la primera y segunda fases; al inicio de la pandemia las compras más populares fueron de alimentos, suministros médicos o de higiene, en las 
últimas semanas la gente se empezó a "acostumbrar" y sus patrones de compra sugieren una adaptación a la cuarentena.

El autor señala que, desde finales de marzo de 2020, la categoría de fitness fue la que más creció en popularidad dentro del sitio de e-commerce, los productos en las sub-categorías de funcionales, pilates y yoga registraron un crecimiento de tres dígitos, con productos como bandas elásticas y cuerdas de saltar entre los más populares. También juegos de mesa y rompecabezas crecieron en $105 \%$ y $40 \%$. Y el uso de plataformas de streaming han crecido de forma importantes desde el inicio de la emergencia de COVID-19, gracias a los esquemas de trabajo remoto, y a la alta demanda de herramientas digitales.

Después del análisis teórico realizado se plantean como hipótesis del presente trabajo las siguientes:

H1. El consumidor de la Cd. de Pachuca ha modificado el lugar de compra habitual de los productos de la canasta básica a consecuencia de las medidas de confinamiento

H2. El consumidor de la Cd. de Pachuca ha modificado la frecuencia habitual de compra de los productos de la canasta básica a consecuencia de las medidas de confinamiento

\section{Método}

El objeto de estudio de la presente investigación son los aspectos concernientes a los hábitos de consumo de los habitantes de la ciudad de Pachuca, Hidalgo y los municipios que integran la zona Metropolitana tenían antes y durante la contingencia que, por causa de la pandemia por COVID-19 obliga al confinamiento a partir de la segunda quincena de marzo de 2020.

La investigación es de tipo cuantitativa, transversal, exploratoria, cuya técnica de recolección principal de datos cuantitativos fue la encuesta en línea. El sujeto de estudio para esta investigación son los hombres y mujeres mayores de 18 años, que pasan el confinamiento en familia o solos, que conocen los hábitos de compra del grupo con el que viven y tienen poder de decisión de compra de los productos que integran la canasta básica mexicana. El sujeto es habitante de las ciudades de Pachuca, Mineral de la Reforma, Mineral el Monte, Epazoyucan, San Agustín Tlaxiaca, Zempoala y Zapotlán de Juárez; en el Estado de Hidalgo, México.

\section{Diseño de la Investigación}

Para el cálculo de la muestra se tomó como población base los datos que el INEGI (2015) presenta como Población Económicamente Activa por Municipio 2015 en Hidalgo, la cual registra el total de personas mayores de 12 años que están activas y ocupadas. Tomando en cuenta la población asentada en el censo, se calcula el porcentaje de población PEA y se determina 
que el total de la población en los Municipios es de 238, 527 personas. Con el uso del calculador de tamaño de la muestra Survey System se encuentra que con un nivel de confianza del $95 \%$, un margen de error de 5.39 y la población de 238,527 es de 330 encuestas a aplicar en la encuesta electrónica.

Por lo que, usando la plataforma de encuestas electrónicas denominada QuestionPro, se diseñó un cuestionario de 41 preguntas. Previo a liberar la encuesta electrónica, se realizó una revisión del cuestionario por investigadores expertos, así como una prueba piloto de al menos 15 personas. Posteriormente se afinaron las preguntas del instrumento y se liberó la encuesta del 14 al 21 de junio del 2020; consiguiendo que se completaran 345 cuestionarios, cubriendo los que se requerían para dar validez y confiabilidad estadística al proyecto.

\section{Hallazgos}

El estudio se llevó a cabo en el mes de junio de 2020, con una muestra de 345 personas encuestadas. De las cuales el 65\% fueron mujeres y el 35\% hombres. La edad promedio de los encuestados fue de 38 años, la distribución por rangos se presenta en la Tabla No. 1.

Tabla 1. Edad de los encuestados

\begin{tabular}{cc}
\hline Rango & Frecuencia \\
\hline $16-23$ & 69 \\
$24-31$ & 72 \\
$32-39$ & 31 \\
$40-47$ & 80 \\
$48-56$ & 63 \\
$57-64$ & 24 \\
$65-72$ & 5 \\
$73-82$ & 1 \\
Promedio & 37.9 \\
\hline
\end{tabular}

Fuente: Elaboración propia (2020)

El estado civil de los encuestados representa el $48 \%$ como soltero, el $35 \%$ casado, el $7 \%$ en unión libre, el $9 \%$ divorciado o separado y el $1 \%$ viudo. Cabe observar que la encuesta gira en torno a las personas que viven con la persona encuestada, ya sean sus compañeros de vivienda o familia.

En el nivel de estudios de las personas encuestadas predomina el nivel licenciatura con el $53 \%$ de los encuestados, seguida por el $25 \%$ con posgrado y el $20 \%$ con nivel medio superior; el $2 \%$ restante fueron personas con nivel primaria y secundaria.

En ocupación se puede observar que aproximadamente el $37 \%$ es empleado del sector público, el $20 \%$ estudiante y el $15 \%$ empleado de empresa privada. 
El nivel mensual de ingresos de todas las personas que aportaban en el hogar, el $26 \%$ declaró percibir entre $\$ 6,001$ y $\$ 10,000$ pesos al mes, el $24 \%$ entre $\$ 10,001$ y $\$ 20,000$ pesos; solo el $13 \%$ estaba por encima de los $\$ 20,000$ y el $15 \%$ por debajo de los $\$ 6,000$ pesos. Los resultados totales se observan en la Tabla 2.

Tabla 2. Ingreso Mensual en el Hogar

\begin{tabular}{lc}
\hline Ingreso Mensual en el Hogar & Frecuencia \\
\hline Menos de 6,000 pesos & 51 \\
Entre 6,001 y 10,000 pesos & 89 \\
Entre 10,001 y 20,000 pesos & 82 \\
Entre 20,001 y 30,000 pesos & 45 \\
Más de 30,001 pesos & 45 \\
No deseo contestar & 32 \\
\hline
\end{tabular}

Fuente: Elaboración propia (2020)

Con respecto a las personas que habitan los hogares durante la pandemia, la Figura 2 nos muestra los resultados obtenidos:

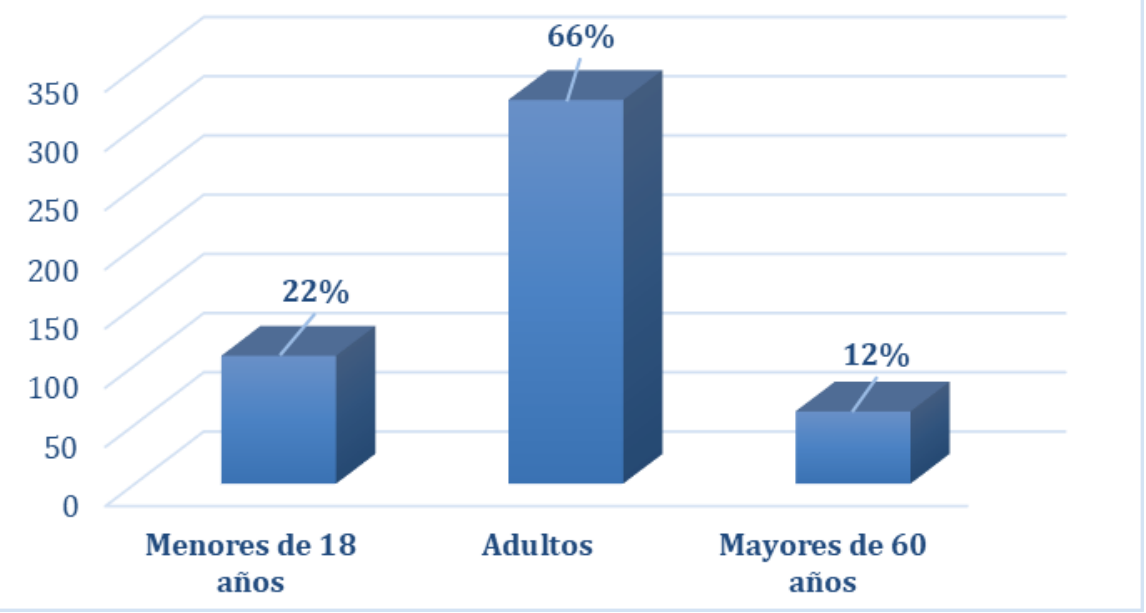

Fuente: Elaboración propia (2020)

Se puede observar que durante la contingencia, en el número de habitantes por cada hogar predomina con el $66 \%$ los adultos, el $22 \%$ los menores de edad y solo el $12 \%$ las personas de la tercera edad. 


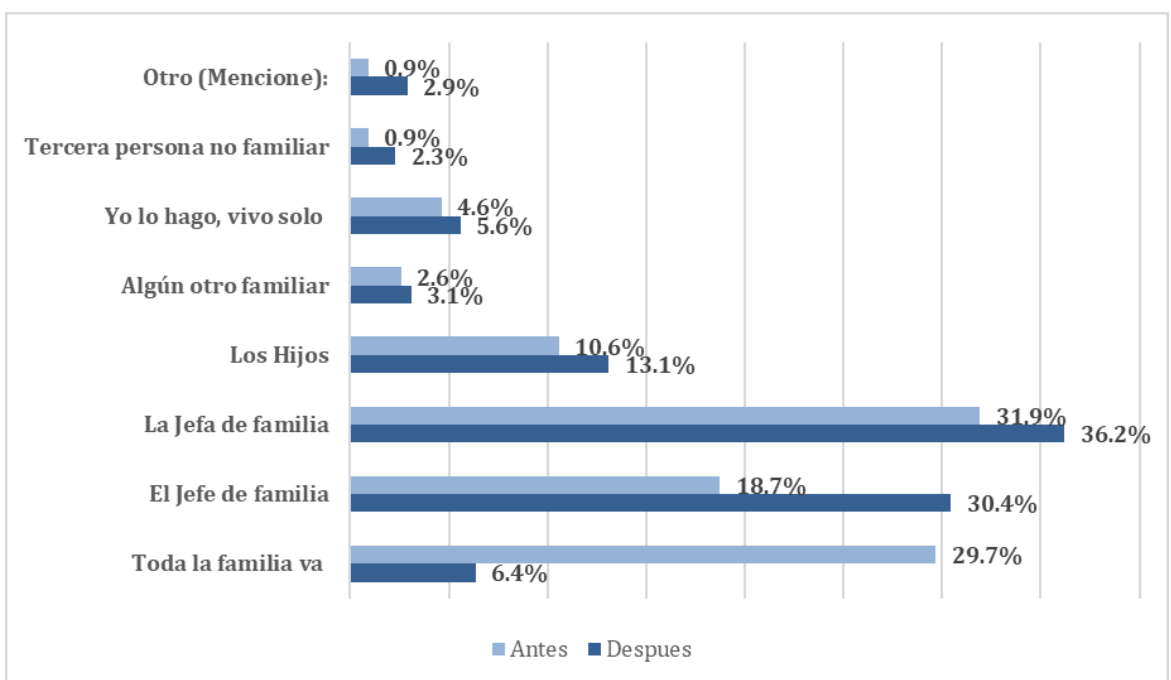

Figura 3. Persona responsable de realizar las compras del hogar antes y durante la cuarentena.

Fuente: Elaboración propia (2020)

Se le preguntó a los encuestados para el caso de antes y durante la cuarentena, quien o quienes eran los responsables de realizar las compras de los productos necesarios para el hogar. En la Figura 3 se puede observar que antes de la pandemia en el casi $30 \%$ de los casos toda la familia solía ir a realizar las compras, durante la pandemia solo el 6\% reporta seguir haciéndolo. Es interesante ver que la participación del jefe de familia y de la jefa de familia, sube en porcentaje en el antes y después de la pandemia.

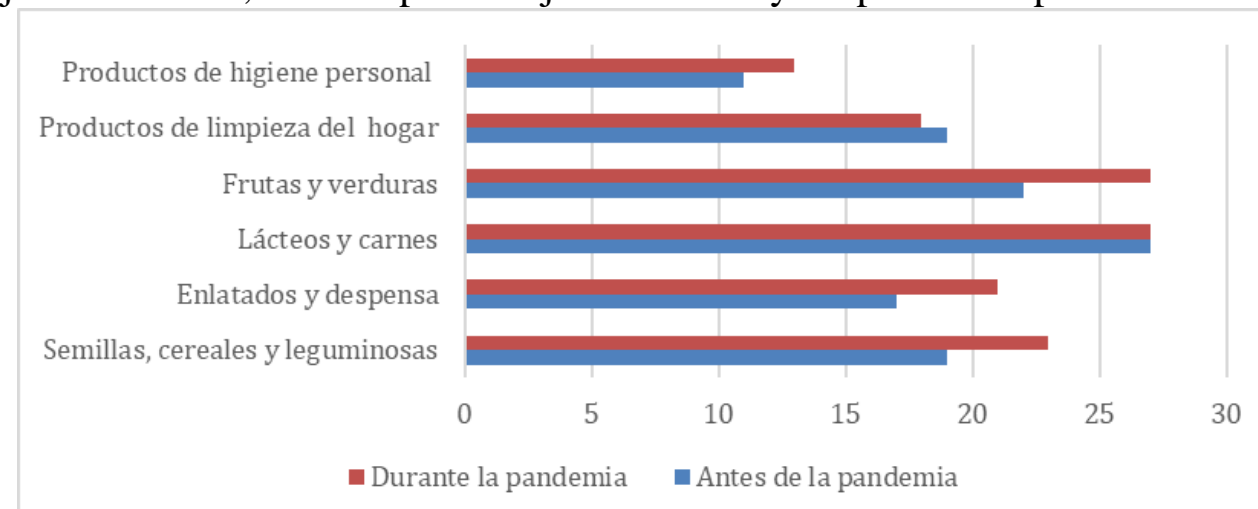

Figura 4. Tiendas de conveniencia, como lugar de compra de artículos de la canasta básica. Bienes seleccionados de preferencias.

Fuente: Elaboración propia (2020)

Como puede observarse en la Figura 4, durante el periodo de la pandemia, la población encuestada aumentó su visita a las tiendas de abarrotes, fruterías y carnicerías cercanas a su vivienda a realizar sus compras de los 
productos de la canasta básica destacando las mercancías relacionadas con las frutas y verduras, así como los enlatados y despensa en general, con lo cual se presenta una oportunidad para estos pequeños negocios para retener a estos clientes que ahora se están acercando a sus servicios. Además de ello, el 79\% de las personas encuestadas manifestaron que estarían dispuestos a continuar visitando estos pequeños negocios cercanos a sus hogares.

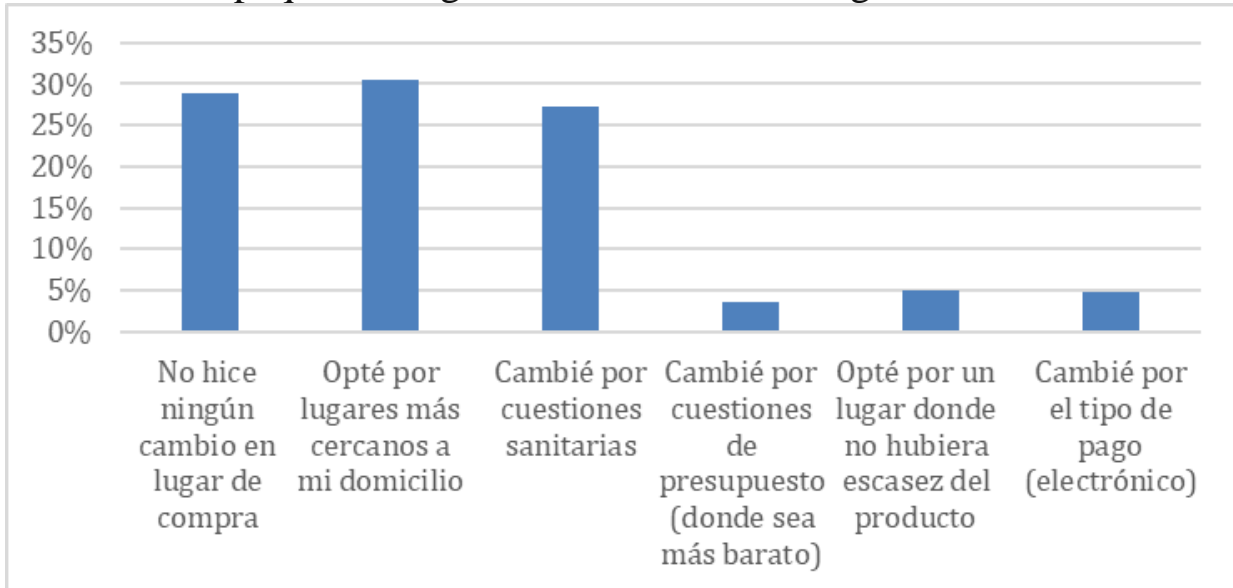

Figura 5. Razones de cambio del lugar de compra de los productos de canasta básica (\%). Fuente: Elaboración propia (2020)

Como se observa en la Figura 5, el aumento de las visitas a los pequeños comercios próximos a las viviendas de los consumidores, en el contexto de la pandemia, tuvo como origen principalmente la cercanía del comercio, así como el factor sanitario, elementos que los encuestados ponderaron para tratar de minimizar el riesgo de contraer el virus COVID-19, cabe resaltar que el $29 \%$ de los encuestados no realizó cambio alguno en el lugar de compra de sus productos de la canasta básica.

Tabla 3. Frecuencia de compra de productos de la canasta básica. Bienes seleccionados.

\begin{tabular}{|c|c|c|c|c|}
\hline $\begin{array}{c}\text { Variables } \\
\text { Frecuencia } \\
\text { de Compra } \\
\end{array}$ & Antes & Porcentaje & Durante & Porcentaje \\
\hline Semillas, & Semanalmente & 39 & Semanalmente & 28 \\
\hline $\begin{array}{c}\text { Cereales y } \\
\text { leguminosas }\end{array}$ & $\begin{array}{l}\text { Quincenalmente } \\
\text { o mensualmente }\end{array}$ & 53 & $\begin{array}{l}\text { Quincenalmente } \\
\text { mensualmente }\end{array}$ & 65 \\
\hline & Semanalmente & 36 & Semanalmente & 22 \\
\hline Despensa & $\begin{array}{l}\text { Quincenalmente } \\
\text { o mensualmente }\end{array}$ & 60 & $\begin{array}{l}\text { Quincenalmente } \\
\text { mensualmente }\end{array}$ & 72 \\
\hline $\begin{array}{l}\text { Frutas y } \\
\text { Verduras }\end{array}$ & $\begin{array}{l}\text { Cada tercer día } \\
\text { Semanalmente o } \\
\text { quincenalmente }\end{array}$ & 14 & $\begin{array}{l}\text { Cada tercer día } \\
\text { Semanalmente } \\
\text { quincenalmente }\end{array}$ & 11 \\
\hline
\end{tabular}

Fuente: elaboración propia (2020) 
Por otra parte, como consecuencia de las condiciones sanitarias expuestas, y del temor de los consumidores a contagiarse del COVID-19, la población encuestada optó por visitar los lugares de compra de sus productos de consumo básico, de manera más espaciada en el tiempo. Las visitas que realizaba de manera semanal para adquirir estos productos antes del periodo de la pandemia se vieron reducidas y optaron por aumentar estas visitas de manera quincenal o incluso de manera mensual (Ver Tabla 3).

\section{Discusión}

En esta investigación se documentan algunos hábitos de compra del consumidor radicado en el estado de Hidalgo, México, particularmente asentados en la ciudad de Pachuca y su zona Metropolitana, en el contexto de la contingencia sanitaria ocasionada por el virus COVID-19 durante 2020. Los encuestados representaron un hogar en confinamiento durante el periodo de la pandemia en 2020, ya fuera que vivieran con familiares o compañeros de vivienda. Como principales hallazgos se encontró que en un $41 \%$ de los hogares, los ingresos fueron menores de 20,00 pesos mensuales, los habitantes de la vivienda en un $88 \%$ representaban población adulta y menores de edad. El cambio en las personas que realizan las compras para el hogar tuvo modificación significativa, principalmente una importante disminución en el aspecto de que antes de la pandemia toda la familia acostumbraba a realizar las compras, siendo tanto una actividad de consumo como de recreación; con el confinamiento la figura del jefe de la casa como el encargado de salir y hacer las compras del hogar se duplica y, en cuanto a la jefa del hogar como la responsable de las compras no tienen un importante cambio en el porcentaje. Otro hallazgo significativo es que en el rubro de los productos de la canasta básica no sufrieron cambios importantes con respecto a la preferencia y cantidad de compra que se hacia antes y durante la pandemia.

Entre otros hábitos que se reportan con cambios que tiene un alto grado de importancia es que es que los consumidores prefieren para la compra de productos de la canasta básica las tiendas de abarrotes, fruterías y carnicerías cercanas a su hogar, debido a causas de disminuir la movilidad y mayor seguridad sanitaria. Como se puede observar, este hallazgo se relaciona con lo que se señala en los antecedentes de la investigación en cuanto a que los consumidores rumanos modificaron su lugar y canal de compra de productos agrícolas, por cuestiones de mantener una sana distancia y minimizar las posibilidades de contagio del virus.

Los consumidores estudiados en esta investigación manifiestan en un importante porcentaje que están dispuestos a continuar comprando los productos básicos en estos pequeños negocios aún y después de la pandemia, lo cual también es similar con lo señalado en el estudio europeo. 
Un segundo hallazgo tiene que ver con la frecuencia de compra de los productos de la canasta básica, observándose que, durante este periodo de crisis sanitaria, la población estudiada manifestó que sus visitas al lugar de compra se han realizado más espaciadas temporalmente. Estos hallazgos tienen congruencia con lo que anteriormente se señaló de los consumidores de Barcelona y Rumania, en el cual experimentan disminución en la frecuencia de compra.

Como se puede observar, los hallazgos encontrados tienen congruencia con los estudios que al momento de la investigación se han realizado tanto nacional como internacionalmente y que corresponden a la tendencia que se esta desarrollando como resultado del confinamiento por la pandemia.

\section{Conclusiones}

La pregunta de investigación que orientó a la presente investigación estuvo planteada en los siguientes términos ¿Han cambiado los hábitos de compra de los productos de la canasta básica del consumidor de la $\mathrm{Cd}$. de Pachuca, Hidalgo México, en términos de lugar y frecuencia como consecuencia del confinamiento de la pandemia por COVID-19?

Una primera conclusión, es que se observó que las personas dan prioridad a su seguridad y salud física, de tal manera que satisfacen sus necesidades básicas buscando aquellos canales, lugares y productos que les proporcionen la confianza en que estarán protegidos y saludables del virus en cuestión.

Las dos hipótesis planteadas en la investigación no fueron rechazadas, por lo que, los resultados concluyen que los consumidores de la región de estudio han puesto su mirada en las pequeñas tiendas de abarrotes, carnicerías y fruterías, como una opción para realizar sus compras de los productos de la canasta básica, considerando la posibilidad de continuar acudiendo a ellas aun después de que esta crisis sanitaria sea superada. Por otra parte, se concluye que la frecuencia de compra de estos productos ha ido disminuyendo y ahora las compras que se hacían semanalmente antes de la pandemia han pasado a ser quincenal o incluso mensualmente. También, cabe mencionar que las personas que realizan las compras han cambiado como resultado de esta contingencia, siendo los jefes y jefas de familia los que salen y realizan las compras para todos los habitantes del hogar.

Con estos resultados se aporta información referente al comportamiento del consumidor en un país en desarrollo y en un contexto particular de la sociedad, el de una pandemia que ha trastocado los patrones de conducta de las personas en una gran cantidad de ámbitos. Este estudio abre la posibilidad a nuevas investigaciones que podrían ir encaminadas a documentar los nuevos hábitos de compra en términos de otras categorías como formas de pago, productos o marcas más aceptadas en este contexto, o 
la exploración de nuevos canales de compra para las familias y consumidores de países en vías de desarrollo.

\section{References:}

1. Analíticade Retail (2018). Hábitos de consumo: que son, tipos y claves para conocerlos. Analítica de Retail. http://analiticaderetail.com/habitos-de-consumo/

2. Assael, H. (1999). Comportamiento del consumidor. 6ta. Edic., Thomson Edit. México.

3. Butu, A., Brumă, I. S., Tanasă, L., Rodino, S., Vasiliu, C. D., Doboș, S., \& Butu, M. (2020). The impact of COVID-19 crisis upon the consumer buying behavior of fresh vegetables directly from local producers. Case study: The quarantined area of Suceava County, Romania. International Journal of Environmental Research and Public Health, 17(15), 1-25. https://doi.org/10.3390/ijerph17155485

4. Camacho, C. (2016). El neuromarketing y su relación con la jerarquía de las necesidades de Abraham Maslow. Contribuciones a la economía.

researchgate.net/publication/319457110_El_Neuromarketing_y_su_r elacion_con_la_Jerarquia_de_las_Necesidades_de_Abraham_Maslo w.

5. Centro de investigación de mercados (2020). Hábitos de consumo. CIM [Web]. http://www.ciminvestigacion.com/habitos-de-consumo2/

6. Chávez, A. (2020). Esto fue lo que compraron durante la fase dos de COVID-19 los consumidores de México. Merca 2.0 [Web]. https://www.merca20.com/esto-fue-lo-que-compraron-durante-lafase-dos-de-la-COVID-19-los-consumidores-de-mexico/

7. Colvin, M. \& Rutland, F. (2008). Is Maslow's Hierarchy of Needs a Valid Model of Motivation. Louisiana Tech University. http://www.business.latech.edu/

8. Consejo Nacional de Evaluación de la Política de Desarrollo Social (2012). CONEVAL. Obtenido de Construcción de las líneas de bienestar.

https://www.coneval.org.mx/Informes/Coordinacion/INFORMES_Y _PUBLICACIONES_PDF/Construccion_lineas_bienestar.pdf

9. Escamilla, O. (2020). Así es como el coronavirus ha modificado los hábitos y el consumo de los mexicanos. Merca 2.0 [Web]. https://www.merca20.com/asi-es-como-el-coronavirus-hamodificado-los-habitos-y-el-consumo-de-los-mexicanos/

10. García, A. (2015). La teoría keynesiana del consumo. Argumentos económicos. https://argumentoseconomicos.com/2015/06/09/la- 
teoria-keynesiana-del-

consumo/\#: :text=Las\%20teor\%C3\%ADas\%20Keynesianas\%20del $\% 20$ consumo,disponible $\% 20$ del $\% 20$ per\%C3\%ADodo $\% 20$ fuese $\% 20$ cero.

11. García, F. (2020). Así es como el consumidor mexicano se siente frente a la pandemia por el COVID-19. Entrepreneur [Web]. https://www.entrepreneur.com/article/349413

12. Instituto Nacional de Estadística, Geografía e Informática - INEGI (2015). Encuesta Intercensal 2015. Obtenido de Hogares y Viviendas: https://www.inegi.org.mx/temas/hogares/IZA BC Staff (3 agosto, 2018). 6 características del consumidor mexicano. IZA Bussines Centers. https://blog.izabc.com.mx/6-caracteristicas-del-consumidormexicano

13. Innovación Económica (2020). Estas son las tendencias de consumo post COVID-2019. Innovación económica.

https://innovacioneconomica.com/estas-son-las-tendencias-deconsumo-post-COVID-19/

14. IZA BC Staff (2018). 6 características del consumidor mexicano. IZA Bussines Centers. https://blog.izabc.com.mx/6-caracteristicas-delconsumidor-mexicano

15. Marina, J. (2012). Los hábitos, clave del aprendizaje. [Blog] https://www.joseantoniomarina.net/articulo/los-habitos-clave-delaprendizaje/

16. Martínez, J. (2019). Hábitos de compra. Liderazgo y mercadeo. El portal de los líderes. https://www.liderazgoymercadeo.co/habito-decompra/

17. Maslow, A. (1943). "Una Teoría de la Motivación Humana" Psychological Review, 50, pp. 370-396.

18. Quintero, A.J. (s/d) TEORÍA DE LAS NECESIDADES DE MASLOW. http://files.franklin-yagua.webnode.com.ve/200000092e266ae35e3/Teoria_Maslow_Jose_Quintero.pdf

19. Survey System (2020). https://www.surveysystem.com/sscalc.htm\#one

20. The Nielsen Company (2020). Coronavirus (COVID-19) y su evolución en el consumo en México. FMCG \& RETAIL. https://www.nielsen.com/mx/es/insights/article/2020/coronavirusCOVID-19-y-su-evolucion-en-el-consumo-en-mexico/

21. Wilkie, W. L. (1994). Consumer Behavior. John Wiley and Sons (WIE) Edit. 